
Publisher: SPRINGER-VERLAG HEIDELBERG, TIERGARTENSTRASSE 17, D-69121
HEIDELBERG, GERMANY

Subject Category: Biochemical Research Methods; Chemistry, Analytical

IDS Number: 746ZJ

ISSN: 1618-2642

DOI: $10.1007 / \mathrm{s} 00216-003-2194-5$

http://www.springerlink.com/content/3cfu6kw6mm2w1b3b/

\title{
SUPERHEATED LIQUIDS FOR THE EXTRACTION OF SOLID RESIDUES FROM WINEMAKING PROCESSES
}

\section{J. González-Rodríguez ${ }^{1}$, P. Pérez-Juan ${ }^{2}$ and M.D. Luque de Castro ${ }^{3^{*}}$}

1 R\&D Department Pérez Barquero, S.A. Avda. de Andalucía, 27, E-14550, Montilla, Córdoba, Spain. Fax: 957 650208, E-mail: barquero@fiab.es

${ }^{2}$ LIEC, Laboratory and Enologic Research of Castilla, Polígono industrial, calle XV, parcela R-113, E-13200, Manzanares (Ciudad Real), Spain. Phone: 34-926647115, E-mail: liec@erasnet.net

3 Department of Analytical Chemistry, University of Córdoba, Campus of Rabanales, Annex C-3, E-14071, Córdoba, Spain. E-mail: qa1lucam@uco.es; Fax:+34 957218615

Solid residues from winemaking process have been subjected to extraction with superheated water-ethanol mixtures. Identification and characterisation of the extracted compounds have been made by spectrophotometry, gas chromatography with either flame ionisation or mass detectors and high performance liquid chromatography with UV detection. The extraction has been performed in a static manner by single or repetitive cycles. All variables affecting the extraction process have been studied and optimised. The extraction time and temperature are $65 \mathrm{~min}$ and $210^{\circ} \mathrm{C}$, respectively. Two phases constitute the extract: an aqueous phase, which is rich in phenol compounds and an oily phase, mainly formed by fatty acids. The method allows manipulation of the extract composition by changing the applied pressure, temperature, water-ethanol ratio and $\mathrm{pH}$. The method is faster than the traditional extraction procedures for obtaining valuable compounds from these residues.

Keywords: solid-liquid extraction, liquid chromatography, gass chromatography, mass spectrometry, superheated liquids, winemaking residues 


\section{Introduction}

After grapes crushing for obtaining the must, latter subjected to the fermentation process, a residue constituted by seeds, peels and shoots from the grape bunch is obtained. This residue is used to obtain a low sugary liquid when mixed with water, and after alcoholic fermentation can be either exploited as raw material to obtain a low quality vinegar or sold to alcohol factories to obtain ethanol. The residue can also be used as fertilizer due to its high nutrition content. The composition of this solid residue varies depending on the variety of grapes, but it is mainly constituted by tannins, organic acids, reducing sugars, nitrogen compounds, anthocyans, wax, inorganic salts and lipids [1], and rest of vegetal cell walls (pectin, cellulose, hemicellullose and mainly lignine).

The extraction of valuable compounds from this raw material is performed on several ways depending on the target compounds to be extracted: anthocyans are extracted by using as extractant either sulphur dioxide or sorbent resins [2]; seeds are previously separated and smashed and the oil is extracted by using hexane as solvent [3]; tannins are extracted with hot water and then precipitated with $\mathrm{NaCl} ;{ }^{4}$ meanwhile simple phenolics (hy-droxylated and methoxylated benzoic acids, cinnamic acid and derivatives and catechins) have been extracted by soaking with organic solvents $[5,6]$.
When extraction is performed in the absence of both light and air, degradation and oxidation processes are significantly reduced in comparison with other extraction techniques, and the extracts obtained are richer in valuable compounds. This is the main advantage of using subcritical or supercritical fluids and one of the reasons for developing extraction processes in this way.

Supercritical and subcritical fluid extraction has been proposed using carbon dioxide and adding organic modifiers to increase the polarity of the fluid for the extraction of phenolic compounds [7,8], but the costs of the methods at an industrial scale are high. The stability of phenolic compounds under subcritical conditions up to $150^{\circ} \mathrm{C}$ using methanol as extractant has been studied by Palma et al. [9] to prove the feasibility of extracting phenolic compounds from solid residues from the winemaking process with pressurised liquids. Although the results were satisfactory, the use of this solvent presents two main shortcomings: the cost of methanol and its high toxicity, which involves a subsequent step for removal of the extractant before human use.

Subcritical water extraction of essential oils from aromatic plants is very promising $[10,11]$. It has prompted the development of an alternative to the conventional manual methods based on organic solvents. The use of superheated ethanol-water mixtures has previously been checked for the extraction of phenolic compounds from 
oak wood [12,13]. The extracts obtained were compared with commercial wood extracts with an excellent agreement concerning composition, and with drastic reduction of both time and costs.

Due to the nature of the compounds that can be found in solid residues coming from winemaking processes, the use of superheated water or mixtures of water and ethanol could be suitable for the extraction of such compounds. The aim of this work is the study of a leaching step for these residues using superheated water or either ethanol-water mixtures on the light of the individual separation of the extracted species by liquid or gas chromatography or the monitoring of the whole extract by a photometric detector.

\section{Experimental}

\section{Instruments and apparatus}

The laboratory-made extractor used, shown in Fig. 1, consists of the following parts: a Knauer 64 high pressure pump (Knauer, Berlin, Germany), used to propel the extractant liquid through the system; a stainless steel cylindrical extraction chamber $(150 \mathrm{x} 11 \mathrm{~mm}$ id, $14 \mathrm{ml}$ internal volume) which was closed with screws at both ends in order to permit its filling with extractant and emptying of the extract. The screw caps also contained stainless steel filters plates $(2 \mathrm{~mm}$ thick, and $6.35 \mathrm{~mm}$ i.d.) to ensure the wood chips remained in the extraction chamber. This chamber, together with a stainless steel preheater, was located in a gas chromatograph oven (HP 5720A, Hewlett-Packard, Wilmington, DE, USA) used as heating source capable to work up to $400^{\circ} \mathrm{C}$.

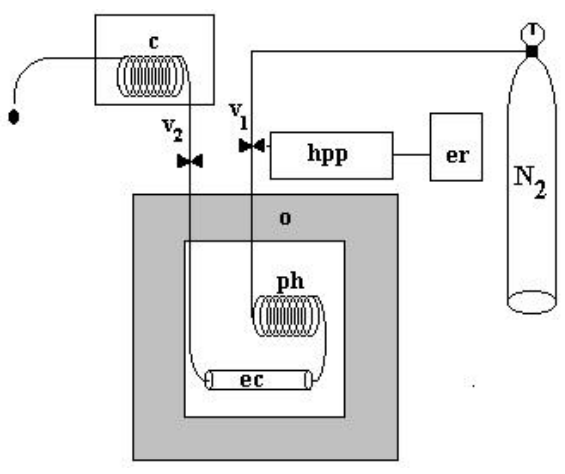

Figure 1. Extraction system. hpp: high pressure pump, er: extractant reservoir, ph: pre-heater, ec: extraction cell, o: oven, c: cooler, $\mathrm{v}_{1}=$ selection valve, $\mathrm{v}_{2}=$ restriction valve.

A loop made from 1-m length stainless-steel tubing and cooled with water at room temperature was used to cool the extract from the oven to a temperature close to $25^{\circ} \mathrm{C}$. A pressure needle valve coupled to the outlet of the cooler and a selecting valve located between the high-pressure pump and the oven allowed flushing of the extract with $\mathrm{N}_{2}$ after extraction.

The liquid chromatography analyses of the extracts were performed using a modular 1100 Hewlett-Packard liquid chromatograph (Pittsburg, PA, USA), consisting of a G1311A high pressure quaternary pump, a G1322A 
vacuum degasser, a 7725 Rheodyne high-pressure manual injection valve (HPIV) and a G1315A diode array detector. The individual separation of the components both from the extracts and standard solutions was performed on a $250 \mathrm{~mm} \times 4.6 \mathrm{~mm}$ id, $5 \mu \mathrm{m}$ particle, Hypersil ODS column (Supelco, Bellefonte, PA, USA) protected by a precolumn of the same material.

The gas chromatography analyses of the extracts were performed using a Varian 3900 gas chromatograph equipped with a Chrompack capillary CPWax $57 \mathrm{CB}$ fused silica column $(50 \mathrm{~m}$ x $0.25 \mathrm{~mm}$ id, $0.2 \mu \mathrm{m}$ film thickness) and a flame ionisation detector (FID). Finally, a Saturn 2200 mass spectrometer (Varian) equipped with a Chrompack capillary CP-Sil 8 CB fused silica column $(50 \mathrm{~m} \times 0.25 \mathrm{~mm}$ i.d. $)$ was used to characterise the compounds. A Cary 50 Conc spectrophotometer from Varian (Mulgrave, Australia), connected to a computer with Cary WinUV v.2.0 ${ }^{\circledR}$ (Varian) software for data collection and treatment, was also used for photometric monitoring of the extracts.

All the extracts were centrifuged using a Selecta (Barcelona, Spain) Mixtasel centrifuge and filtered through $0.45 \mu \mathrm{m}$ Minisart filters from Sartorius (Göttingen, Germany). A vacuum pump (Vac Elut SPS 24, Varian, P.S. Analytical, England) was used for filtering the HPLC solvents. Statistical treatments were made using Statgraphics $^{\mathrm{TM}}$ plus 2.1. for Windows.

\section{Reagents and solutions}

Ethanol 96\% (v/v) PA from Panreac (Barcelona, Spain) and distilled water were used for preparing the waterehanol mixtures used as extractant, with ethanol contents from 0 to $100 \%$. Vanillin and gallic, protocatechuic and vanillic acids used as chromatographic standards were from Sigma-Aldrich (St. Louis, USA). 4-methyl-2-pentanol and picolinic acid ethyl ester used as internal standards were from Merck (Darmstadt, Germany). Solutions of methanol, acetic acid (both HPLC grade and supplied by Merck) and ultrapure water at $\mathrm{pH} 3$ were used as mobile phases. Methanol and ultrapure water at $\mathrm{pH} 7.0$ were used for conditioning and regeneration of the chromatographic column.

Ultrapure water obtained from a Millipore (Bedfore, MA, USA) Milli-Q plus system was also used. The nitrogen used for dragging the extract from the extraction cell was supplied by AirLiquide (Paris, France).

Solid residues from winemaking process (SRWP) were provided by Pérez Barquero Winery (Montilla, Córdoba) from the 2002 vintage.

\section{Procedures}

\section{Subcritical extraction}

The sample cell in Fig. 1 was filled with $1.5 \mathrm{~g}$ of SRWP, and two pieces of Albet 235 filter paper were inserted at both ends of the cell to prevent the frit from clogging. After assembling the extraction cell in the oven, this was brought up to the working temperature 
$\left(200^{\circ} \mathrm{C}\right)$ and pressurised up to $40 \mathrm{~atm}$ with water-ethanol solution, by maintaining valve $v_{2}$ closed. Once the system was pressurised, valve $\mathrm{v}_{1}$ was closed and a static extraction was developed for $60 \mathrm{~min}$. After this, $\mathrm{v}_{1}$ was turned to the open position to allow nitrogen to flow through the cell by opening valve $\mathrm{v}_{2}$; then, collecting the extract in a vial at room temperature.

\section{Chromatographic separation and detection}

For the optimisation study $2-\mu \mathrm{L}$ aliquots of the extract were injected into the chromatograph in the $(1: 15)$ split mode. The flow-rate of the carrier

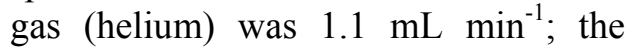
injector and detector temperatures were set at $270^{\circ} \mathrm{C}$; the oven temperature program was: $40^{\circ} \mathrm{C}(5 \mathrm{~min}), 40^{\circ} \mathrm{C}$ to

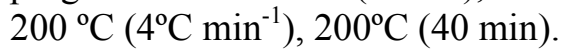

For characterisation of the volatile fraction of the extract, an aliquot of 1 $\mu \mathrm{L}$ of extract was injected into the chromatograph/mass spectrometer in the splitless mode. The carrier gas (helium) flow-rate was $1 \mathrm{~mL} \mathrm{~min}^{-1}$; injector and detector temperatures were set at 270 and $300^{\circ} \mathrm{C}$, respectively; the oven temperature program was: $40^{\circ} \mathrm{C}(5$ $\min ), 40^{\circ} \mathrm{C}$ to $200^{\circ} \mathrm{C}\left(6^{\circ} \mathrm{C} \mathrm{min}^{-1}\right), 200^{\circ} \mathrm{C}$ (20 $\mathrm{min}), 200^{\circ} \mathrm{C}$ to $275^{\circ} \mathrm{C}\left(10^{\circ} \mathrm{C} \mathrm{min}^{-1}\right)$.

For characterisation of the polyphenol fraction $20 \mu \mathrm{L}$ of the extract was injected into the liquid chromatograph. The elution was performed in isocratic mode, a flow rate of $0,3 \mathrm{~mL} \mathrm{~min}{ }^{-1}$, with a mobile phase consisting of 10:90 methanol/water corrected at $\mathrm{pH} 3$ by using the proper amount of acetic acid.
The absorption wavelengths were set at 280 and $310 \mathrm{~nm}$ and UV spectra in the range 220-360 $\mathrm{nm}$ were also recorded. The chromatographic peaks were identified by comparing their retention times and UV spectra with those from the reference compounds.

\section{Results and discussion}

A static approach was tested for the extraction of compounds from SRWP in order to enlarge the sampleextractant contact, thus favouring the attainment of the partition equilibrium.

\section{Optimisation of variables}

The variables affecting subcritical extraction were studied in order to maximise the yield of compounds extracted from SRWP in a time as short as possible. With this aim, a multivariate approach was used for optimising the physical variables affecting the extraction, and a univariate approach was used for studying the influence on the extraction of the ethanol percent in the extraction mixture. The amount of sample used $(1.5 \mathrm{~g})$ was that necessary to fill the extraction cell. The range over which the variables were studied and the optimum values found are given in Table 1.

A multivariate approach was used for the optimisation of the extraction time and temperature within the ranges 10-70 min and $80-250{ }^{\circ} \mathrm{C}$, respectively. The pressure was that required for maintaining the extractant in liquid state. As the vapour pressures of 
ethanol and water at $200{ }^{\circ} \mathrm{C}$ are 30 and $20 \mathrm{~atm}$, respectively [12], a pressure of $40 \mathrm{~atm}$ was chosen in order to guarantee the liquid state of the extractant in all the experiments. The chromatographic areas of three outstanding compounds characteristic of this kind of residues (namely, vanillin, gallic and acetic acids) was the dependent variable.

Table 1. Results of the optimisation study

\begin{tabular}{lll}
\hline Variable & Tested range & Optimum value \\
\hline Chemical & & \\
\hline EtOH $(\% \mathrm{v} / \mathrm{v})$ & $0-100$ & 40 \\
$\mathrm{PH}$ & $3-10$ & 3 \\
Physical & & \\
\hline Extraction time (min) & $10-70$ & 65 \\
Extraction temperature $\left({ }^{\circ} \mathrm{C}\right)$ & $80-250$ & 210 \\
Sample weight $(\mathrm{g})$ & - & 1.5 \\
Grinded/ungrinded & - & Grinded \\
Pressure (atm) & - & 40 \\
\hline
\end{tabular}

The results from the ANOVA studies and the response surfaces for the experimental design obtained were statistically equal in all cases. The signal increased when the time and temperature were increased but with a higher effect from the former. A time of $65 \mathrm{~min}$ and a temperature of $210^{\circ} \mathrm{C}$ were selected as optimum. Temperatures higher than this were not used in order to avoid cleavage and oxidation reactions of some of the extracted compounds [13,14].

Since the P-value in the ANOVA table is lower than $0.05 \%$, there is a statistically significant relationship between the variables at a $95 \%$ confidence level. The equation of the model chosen in the optimisation is: Area $=1658-325 T+160 t+0.751 T^{2}$ $+1.4 T t-1.55 t^{2}$, where $\mathrm{T}=$ temperature and $t=$ time. The amount of ethanol in the extractant was studied by the univariate method in the range 0 $100 \%(\mathrm{v} / \mathrm{v})$. It was found that maximum extraction of some compounds -e.g. protocatechuic acid- was achieved by increasing the ethanol concentration, as expected, but the concentration of some other compounds such as vanillin and gallic and vanillic acids decreased. Other compounds, such as acetic acid, were not affected by changes in the extractant composition. This behaviour was checked by both liquid chromatography (Fig. 2) and gas chromatography (Fig. 3). On the other hand, photometric monitoring of the extract (Fig. 4) showed an increase of the absorbance at $280 \mathrm{~nm}$ by increasing the ethanol content, which can be attributed to increase of polyphenol contents in the extract. A value of $40 \%$ of ethanol 
was selected as a compromise between

compounds of interest.

the extraction efficiency of all the

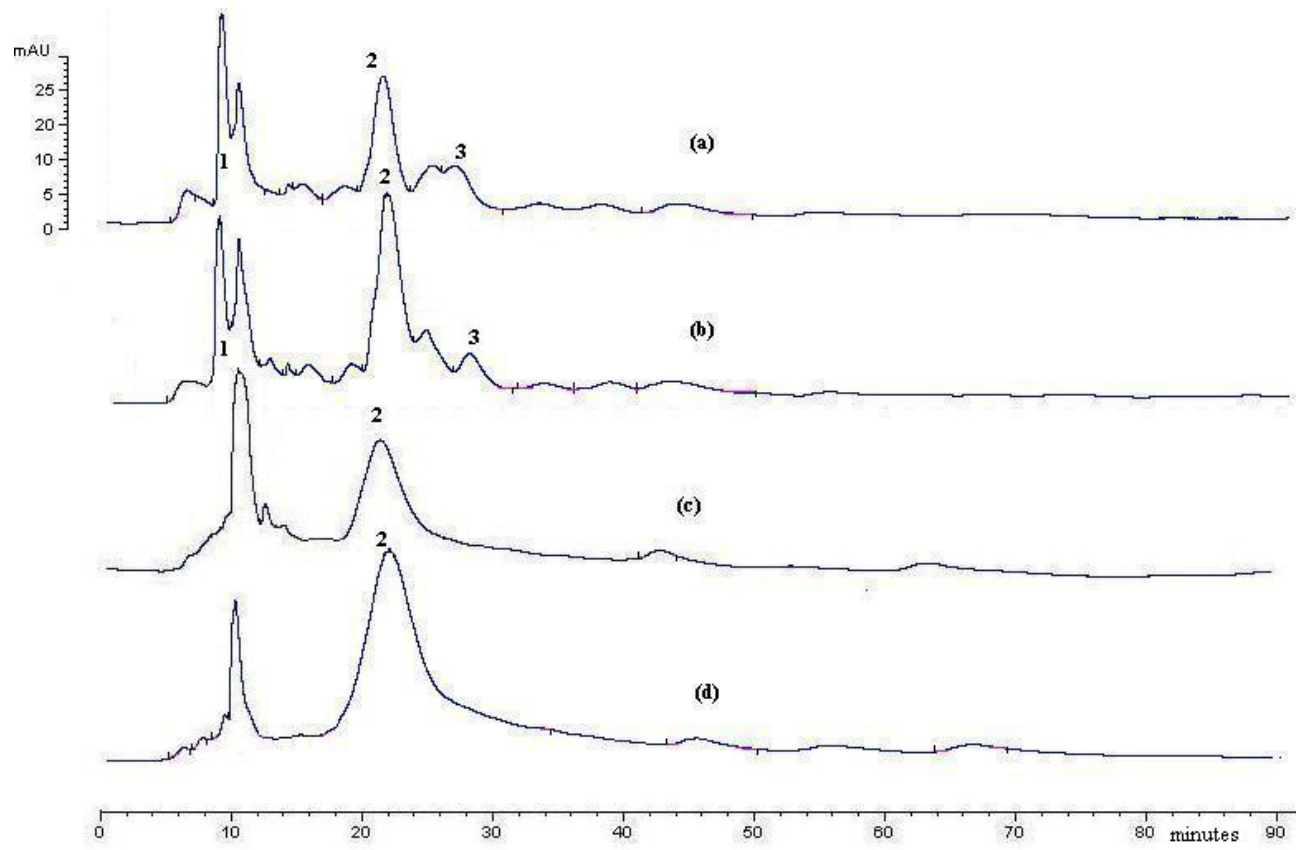

Figure 2. HPLC chromatograms of the extracts obtained with different content of ethanol in the extractant: (a) $20 \%$ (b) $40 \%$ (c) $80 \%$ (d) 100\%. 1. gallic acid, 2. protocatechuic acid, 3. catechin.

A pH study was also developed varying the $\mathrm{pH}$ of the extractant from 2 to 10 . Figure 5 shows the HPLC chromatograms of two extracts obtained by using water at $\mathrm{pH} 10$ (a) and 2 (b). As expected, low pHs favour the extraction of the target compounds in general and that of polyphenols in particular (Fig. 6). This was also the behaviour of some of the components in the volatile fraction as shown by the gas chromatograms (Fig. 7). For exam- ple gallic acid is more efficiently extracted; meanwhile the extraction of vanillin and acetic and vanillic acid is not affected for this variable. The different behaviour could be due to the pK of each particular compound. Grinded and non-grinded residues were subjected to extraction. Higher both polyphenol index and amount of oil were achieved in the extracts from the former. 

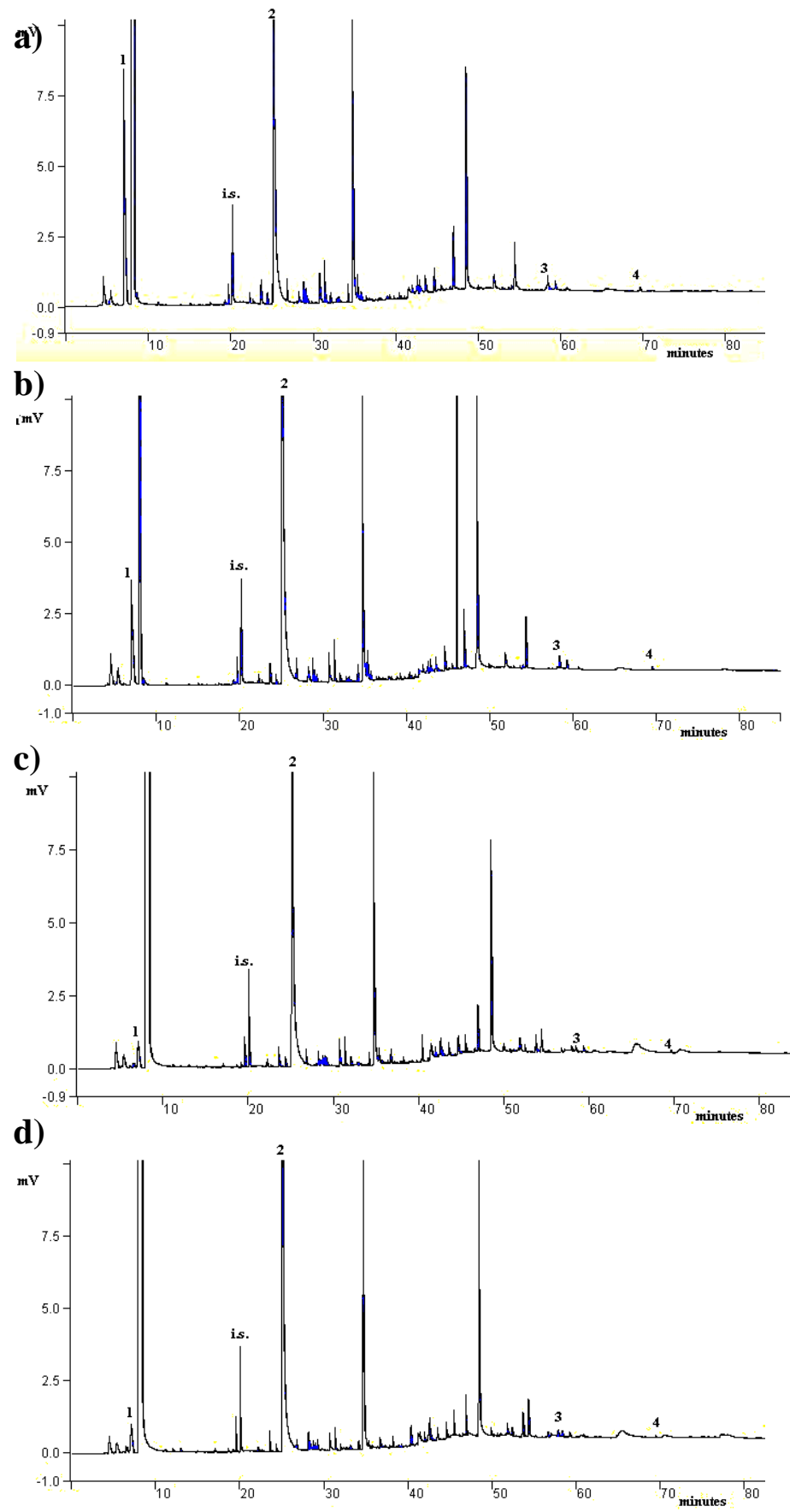

Figure 3. Gas chromatograms of the extracts obtained with different content of ethanol in the extractant: (a) $20 \%$ (b) $40 \%$ (c) $80 \%$ (d) $100 \%$. (1) gallic acid, (2) acetic acid, (3) vanillin (4) vanillic acid. i.s. internal standard 


\section{Composition of the extract}

The subcritical extracts are composed by two phases: aqueous and oily. From $1.5 \mathrm{~g}$ of SRWP, $0.195 \mathrm{~g}$ of oil was obtained, which was constituted mainly by linoleic, estearic, oleic and palmitic acids and their esters. The aqueous phase was rich in polyphenols, fibre and proteins. Proteins and fibre precipitate over a time after extraction and are removed by filtration. The volatile fraction of the extract obtained using the optimum working conditions was characterised by GC/MS. As can be observed in Fig. 8, the majority of compounds in SRWP are volatile phenols and fatty acids. Scarce differences were found in the volatile fraction when extracts from seeds or the overall SRWP were subjected to GC/MS. This denotes a low contribution of peels and shoots to this fraction.

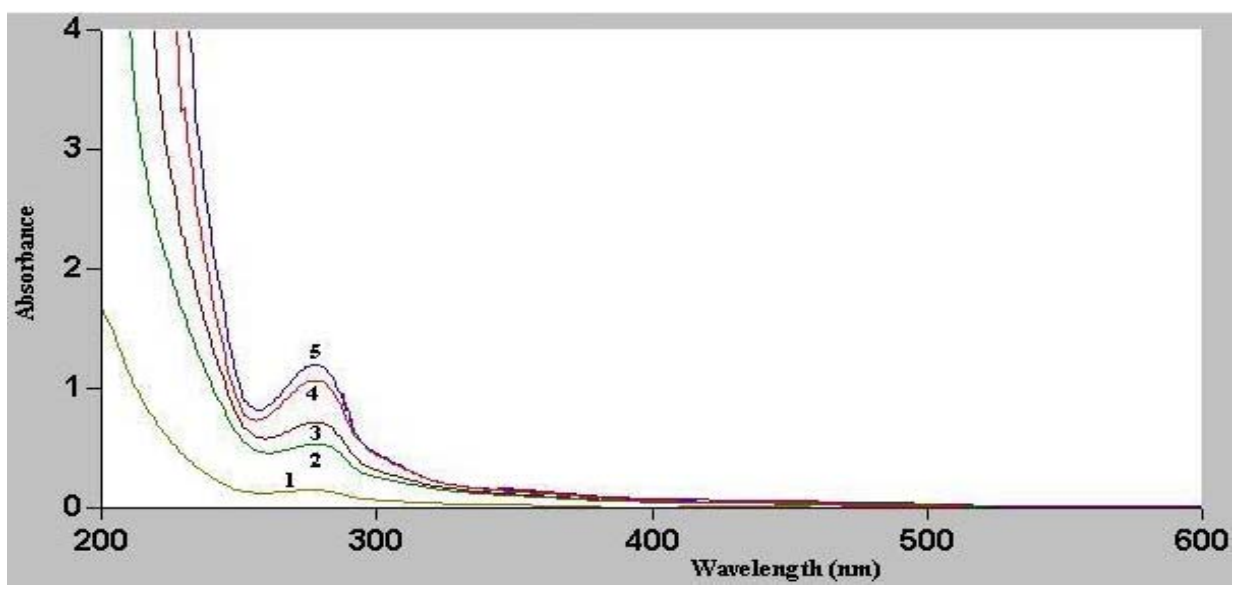

Figure 4. Absorption spectra of extracts with different ethanol contents: $1.0 \%, 2.20 \%, 3$. $40 \%$, 4. $80 \%, 5.100 \%$.

\section{Exhaustive extraction}

A study of exhaustive extraction of the compounds under study in the SRWP sample was performed. Table 2 shows the values for the Total Polyphenols Index and the peak areas from the HPLC chromatograms, referred to the internal standard (picolinic acid ethyl ester), from two of the most outstanding compounds (namely, gallic acid and vanillin). The extractions were performed in three cycles using ethanol/water mixtures with a $10,30,50 \%$ of ethanol content. The extraction percentages for the two compounds ranged between 55$65 \%$ for the first cycle, $15-20 \%$ for the second, $5-15 \%$ for the third. 


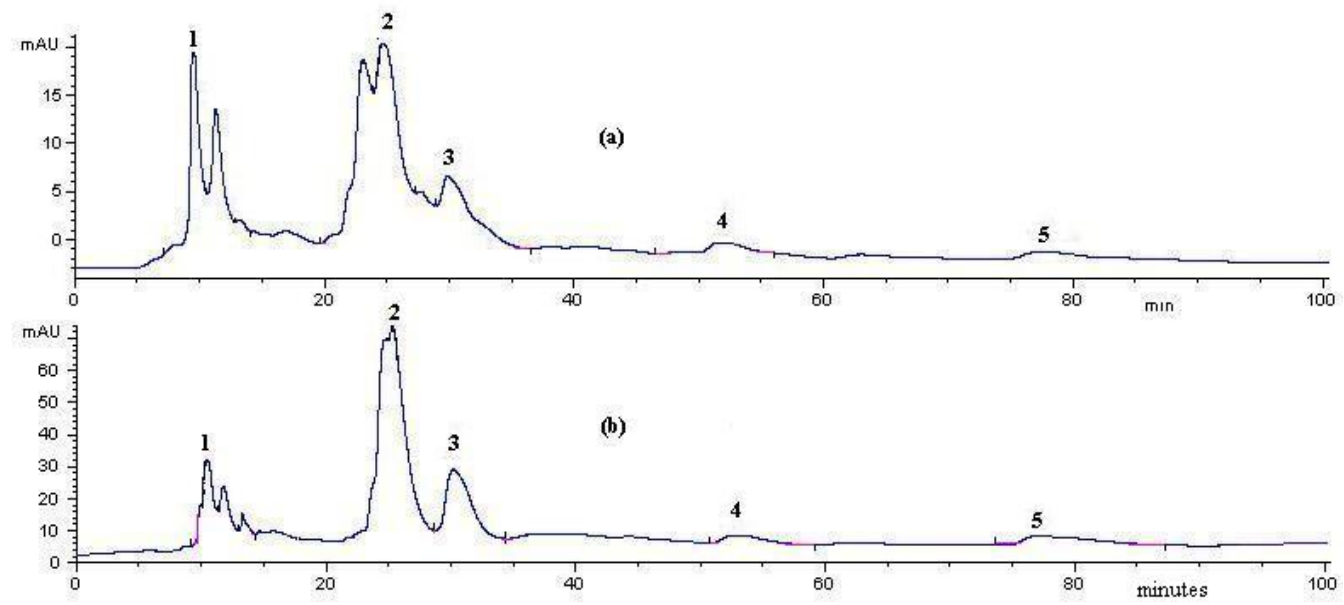

Figure 5. HPLC chromatograms of the extracts obtained at different pHs of the extractant: (a) 10 (b) 2. 1. gallic acid, 2. protocatechuic acid, 3. catechin, 4. vanillic acid, 5. vanillin. Note the difference in the absorbance scales.

\section{Changes of the extract composition}

As previously reported by the authors, the proposed extraction method allows alteration of the composition of the extract by changing extraction para- meters such as temperature, extraction time and, mainly, ethanol percentage and $\mathrm{pH}$ of the extractant. These changes allow the extracts to be enriched in some of the compounds.

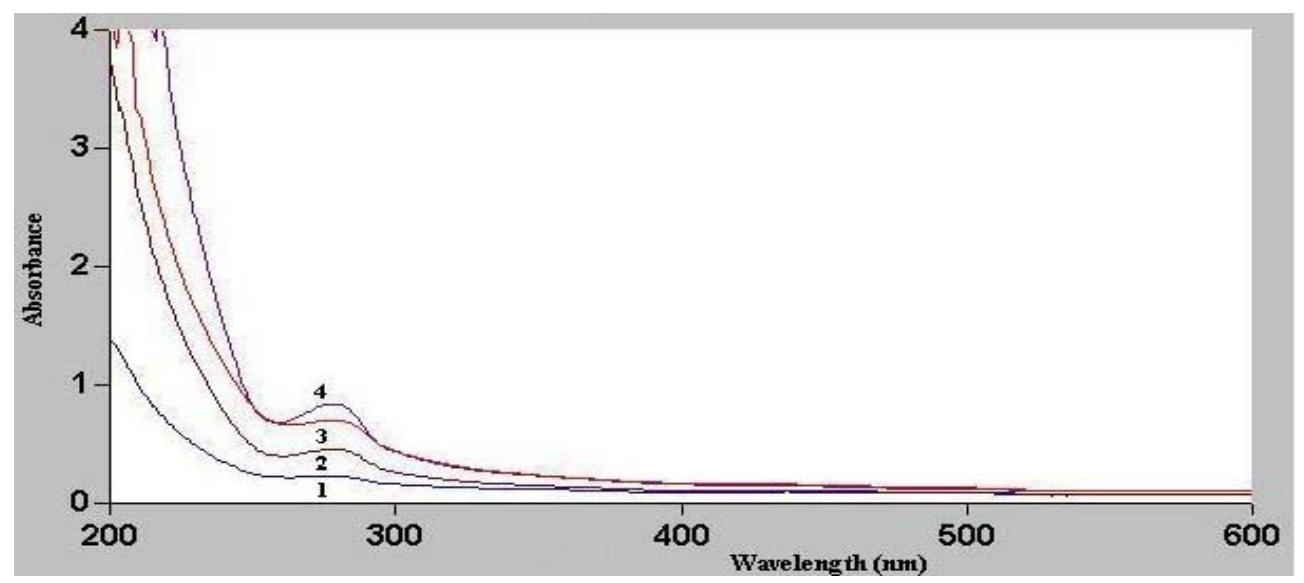

Figure 6. Absorption spectra of the extracts obtained at different $\mathrm{pH}$ values of the extractant: 1.pH=10, 2.pH=9, 3.pH=7, 4.pH=2. 
a)

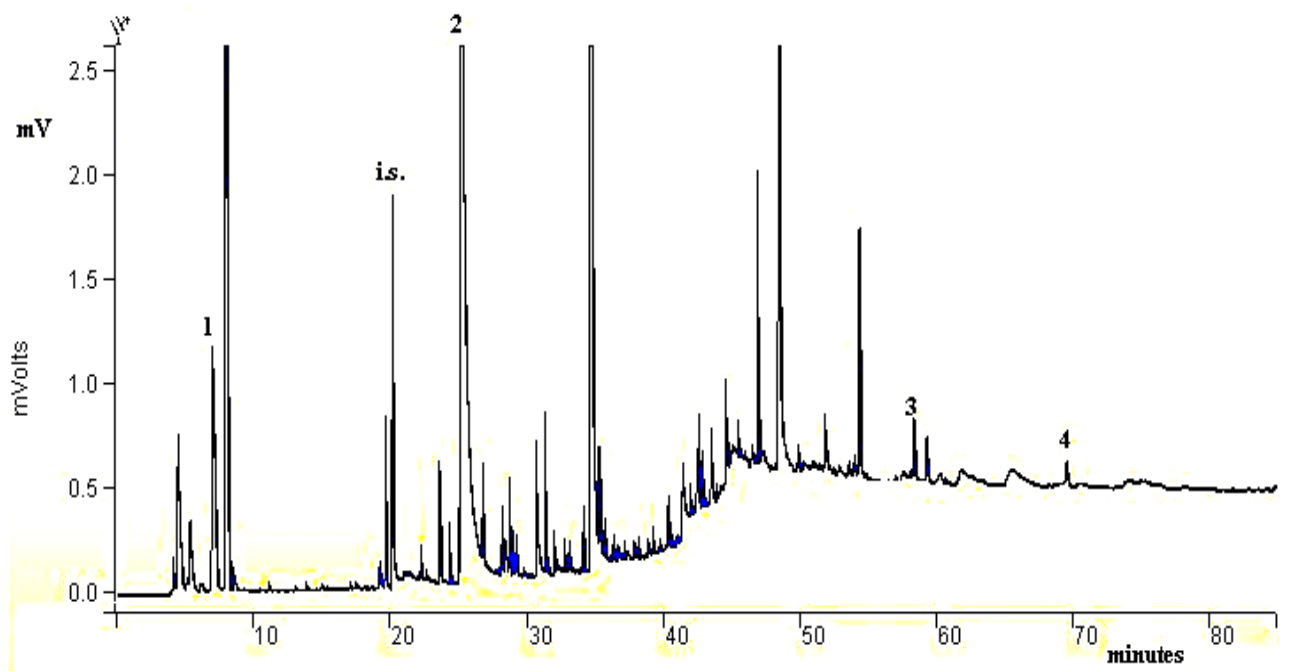

b)

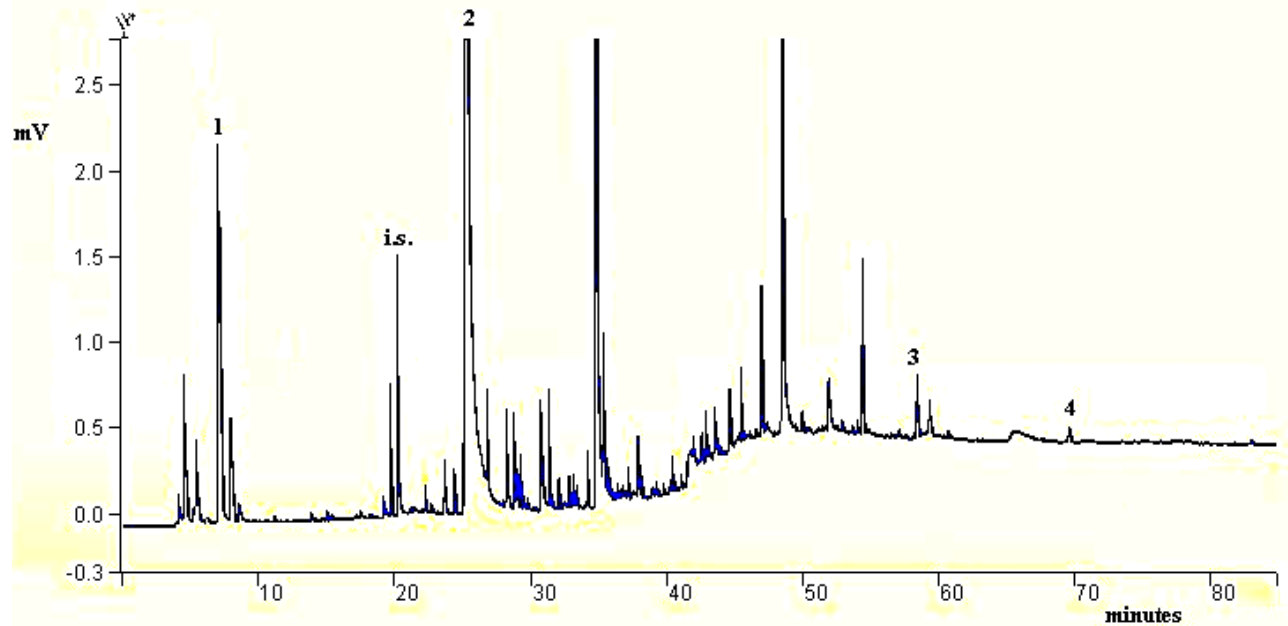

Figure 7. Gas chromatograms of the evolution with the $\mathrm{pH}$ of the extractant: (a) 3 (b) 10. 1. gallic acid, 2. acetic acid, 3. vanillic acid, 5. vanillin. i.s. internal standard. 


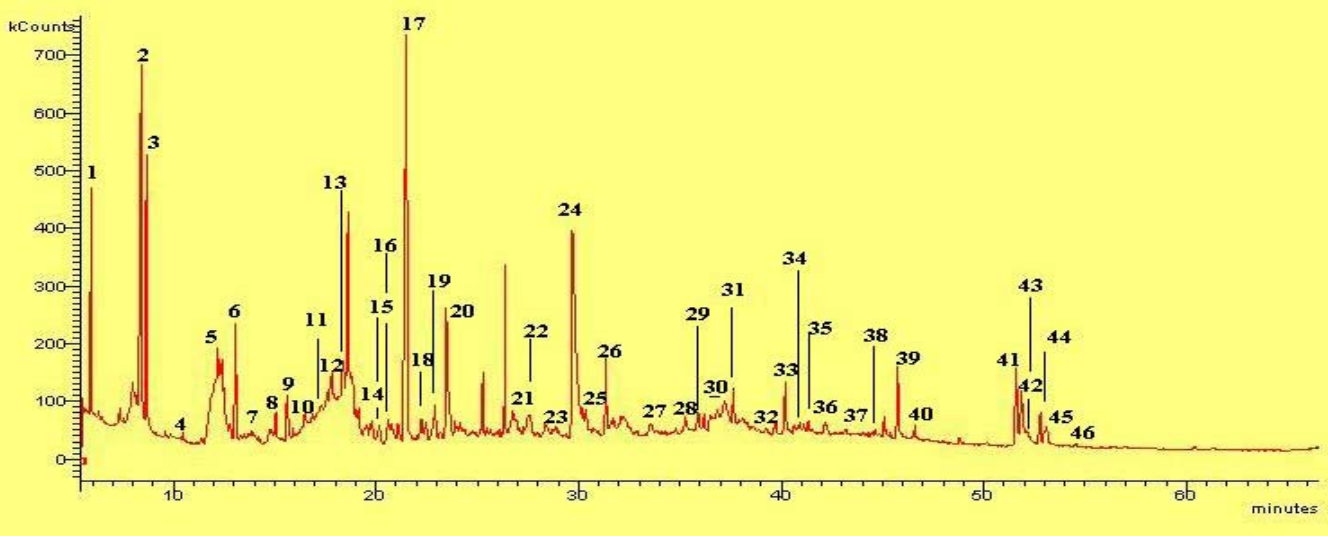

Figure 8. GC-MS chromatograms TIC mode of the subcritical extract at $\mathrm{T}=210^{\circ} \mathrm{C}, \mathrm{P}=40$ atm, $40 \%$ ethanol content and $\mathrm{t}=65 \mathrm{~min}$. Compounds: $1=1$-hydroxy-2-propanone; $2=2$ hydroxy-2-methyl butanoic acid; 3=hydroxybenzoic acid; 4=furanmethanol; 5=diethyl carbonate; 6=ciclohexanone; $7=\gamma$-ketopimelic acid; $8=$ di-n-propyl succinate; 9=methylcyclo-pentenolone; 10=3-furan-carboxilic acid; 11=corilon; 12=butilenglycol diacetate; 13=aletone; 14=2-hydroxy-methyl-furane; 15=glycerol diacetate; 16=maltol; 17=3,5 dihydroxy-2,5-dihydro-piran-4-one.; 18=dihydro-4-hydroxy-2,(3H-furanone); 19=5-hydroxymaltol; 20=pirocatecol; 21=homocatecol; 22=o-acetyl-para-cresol; 23=levoglucosane; 24=pirogalol; 25=vanillin; 26=gallic acid; 27=p-tercbutylcatecol; 28=vanillic acid; 29=dietyl phthalate; 30=monosacharides; 31=homovanillic acid; 32=methyl homovanillate; 33=coniferol; 34= $\alpha$-resorcylic acid; 35=myristic acid; 36=1-dodecen-3-ol; 37=2-hydroxy-5-methylphthaldehyde; 38=ethyl vanillate; 39=palmitic acid; $\mathbf{4 0}=$ ethyl palmitate; $\mathbf{4 1}=$ linoleic acid; 42=oleic acid; 43=estearic acid; 44=ethyl linoleate; 45=ethyl oleate; 46=ethyl estereate; 47=eicosanoic acid.

Table 2. Exhaustive extraction of polyphenols from solid residues from winemaking processes by repetitive cycles as a function of the ethanol percentage in water by using HPLC with UV detector and total polyphenol index monitoring.

\begin{tabular}{|c|c|c|c|c|c|c|c|c|c|}
\hline \multirow{2}{*}{$\begin{array}{l}\text { Water/ethanol } \\
(\% \mathrm{v} / \mathrm{v})\end{array}$} & \multicolumn{3}{|c|}{ cycle $1^{*}$} & \multicolumn{3}{|c|}{ cycle $2^{*}$} & \multicolumn{3}{|c|}{ cycle $3^{*}$} \\
\hline & $\mathrm{G}$ & $\mathrm{V}$ & TPI & $\mathrm{G}$ & $\mathrm{V}$ & TPI & $\mathrm{G}$ & V & TPI \\
\hline $90: 10$ & 23.1 & 9.43 & 61.27 & 11.67 & 4.58 & 32.5 & 3.13 & 1.56 & 5.9 \\
\hline $70: 30$ & 18.2 & 6.29 & 83.53 & 8.92 & 2.89 & 42.1 & 1.63 & 1.38 & 10.2 \\
\hline $50: 50$ & 9.52 & 4.33 & 144.94 & 4.32 & 1.32 & 85.6 & 1.44 & 0.98 & 11.5 \\
\hline
\end{tabular}

* referred to picolinic acid ethyl ester used as internal standard in $\mathrm{mg} \mathrm{l}^{-1}$

$\mathrm{G}=$ galic acid, V=vanillin, TPI= Total Polyphenol Index. 


\section{Conclusions}

The objective of the present work was to check the capacity of subcritical ethanol-water for the extraction of valuable compounds from the solid residue from winemaking process and to characterise the extraction process in order to be used as a clean, cheap and fast alternative to present extraction techniques. Subcritical extraction presents a number of advantages as compared with conventional alternatives, namely: significant saving of organic solvents, possibility of manipulating the composition of the extracts by changing the extraction parameters, lower toxicity, lower costs, safer extraction processes and a simpler technology.

\section{Bibliography}

(1) C. Flanzy, Enología: Fundamentos científicos y tecnológicos. AMV and Mundi Prensa, Madrid, Ed.1, 2000, p. 218.

(2) C. Flanzy, Enología: Fundamentos científicos y tecnológicos. AMV and Mundi Prensa, Madrid, Ed.1,2000, p. 707.

(3) C. Flanzy, Enología: Fundamentos científicos y tecnológicos. AMV and Mundi Prensa, Madrid, Ed.1, 2000, p. 709.

(4) C. Flanzy, Enología: Fundamentos científicos y tecnológicos. AMV and Mundi Prensa, Madrid, Ed.1, 2000, p. 710.
The results of the GC/MS, HPLC/UV detection and GC/FID chromatograms from the extract have shown that some valuable compounds can be obtained from the extracts with a high yield. The studies performed have shown that most of the outstanding volatile and non-volatile compounds can be extracted with only two extraction cycles in percentages ranging from 75 to $95 \%$, which makes feasible industrial exploitation.

\section{Acknowledgments}

The Spanish Comisión Interministerial de Ciencia y Tecnología (CICyT) is thanked for financial support (Project AGL2000-0321-P4-03).

(5) F. Bonilla, M. Mayen, M. Mérida, M. Médina, Food Chem. 1999, 40, 209.

(6) M. Antolovich, P. Prenzler, K. Robards, D. Ryan, Analyst 2000, 125, 989.

(7) M. Palma, L.T. Taylor, J. Chromatogr. A 1999, 849, 117.

(8) M. Palma, L.T. Taylor, Anal. Chim. Acta 1999, 391, 312.

(9) M. Palma, Zulema Piñeiro, Carmelo G. Barroso, J. Chromatogr. A 2001, 921, 169.

(10) R. Soto-Ayala, M.D. Luque de Castro, Food Chem. 2001, 75, 109.

(11) L. Gámiz-Gracia, M.D. Luque de Castro, Talanta 2000, 51, 1179.

(12) R.H. Perry, D.W. Green, J.O. Mahoney, in: Perry's Chemical 
Engineers'Handbook, Vol.1, McGraw-Hill, New York, $6^{\text {th }}$ Edn, 1984.

(13) J. González-Rodríguez, P.M. Pérez-Juan, M.D. Luque de Castro, Chromatographia 2003, $57,5$.

(14) J. González-Rodríguez, P.M. Pérez-Juan, M.D. Luque de Castro, J. Chromatogr. A (Sent for publication). 